\title{
Erratum to: New C2 synchondrosal fracture classification system
}

\author{
Jerome A. Rusin ${ }^{1,2} \cdot$ Lynne Ruess $^{1,2} \cdot$ Robert S. Daulton ${ }^{1}$
}

Published online: 3 July 2015

(C) Springer-Verlag Berlin Heidelberg 2015

\section{Erratum to: Pediatr Radiol}

\section{DOI 10.1007/s00247-014-3224-5}

The caption for Figure 1 incorrectly describes parts (b) and (c). The correct caption is reprinted below
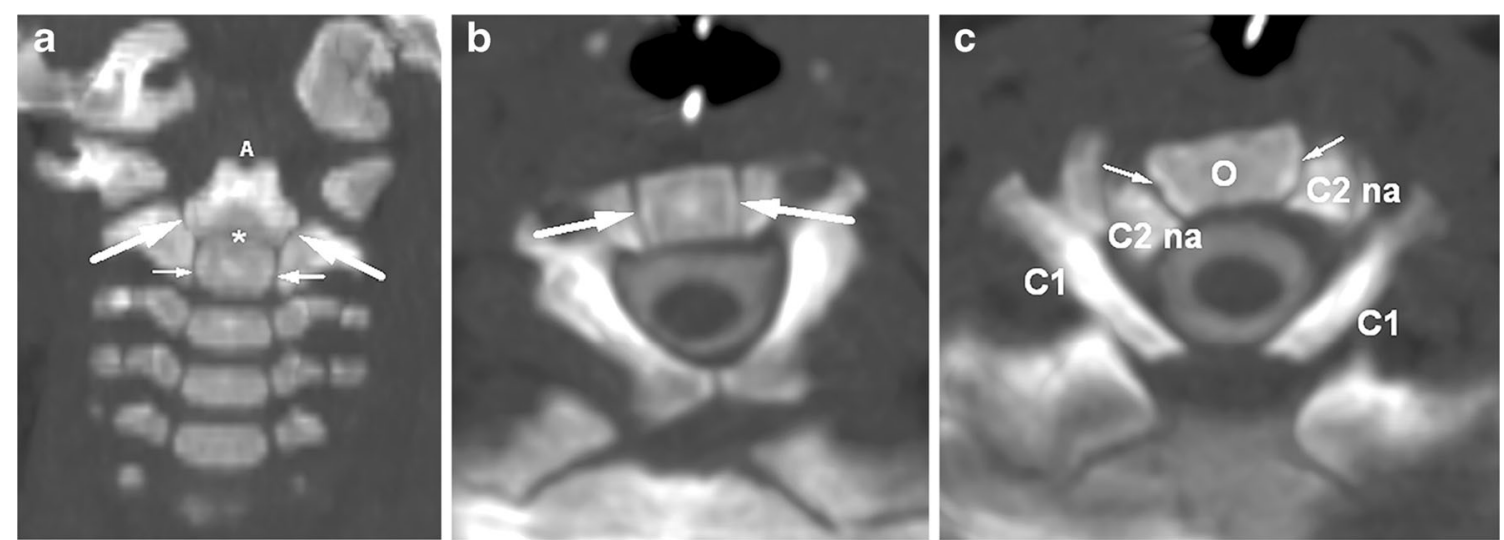

Fig. 1 Normal synchondroses. a Coronal CT image in a 12-month-old boy shows the five central $\mathrm{C} 2$ synchondroses - bilateral neurocentral (small arrows), bilateral odontoneural (large arrows) and the single transverse odontocentral synchondrosis (asterisk) - are all open. The apicodental synchondrosis $(A)$ is also open and os odontoideum is not yet ossified. b, c Axial CT myelogram images in 6-month-old boy show normal immature $\mathrm{C} 2$ anatomy - bilateral neurocentral (large arrows in b) and bilateral odontoneural (small arrows in c). $\mathrm{C} 2$ neural arches $(C 2$ $n a), \mathrm{C} 1$ lamina $(C 1)$ and the odontoid $(O)$ are labeled for reference

The online version of the original article can be found at http://dx.doi.org/ 10.1007/s00247-014-3224-5.

Lynne Ruess

Lynne.Ruess@nationwidechildrens.org

1 Department of Radiology, Nationwide Children's Hospital, 700 Children's Drive, Columbus, $\mathrm{OH} 43205$, USA

2 The Ohio State University College of Medicine and Public Health, Columbus, OH, USA 